contribution to labor history. It was also suggested that efforts be continued to attract historians of non-Western areas.

In addition, much discussion centered on the relationship between labor history and the contemporary labor movement. A panel was suggested on the political responsibility of labor historians to the labor movement. Some of the discussants were critical of the idea, but the energy of the discussion suggested an interest in the topic.

The labor section of the convention drew a variety of papers that more than filled the allotted spots. Walter Licht (University of Pennsylvania) is the program committee representative for the labor and industrialization network for the 1988 convention. Inquiries concerning the panels should be referred to Professor Licht in care of the Department of History. Since whole panels are the easiest to manage, it is advised that prospective participants send proposals only after the panel has been assembled.

\title{
Women in Dark Times
}

\author{
Mary Nolan \\ New York University
}

"Women in Dark Times" was the theme of a conference organized by Claudia Koonz held at the Rockefeller Conference Center in Bellagio, Italy, in August 1987. Twentyfive scholars from the United States, England, Germany, Italy, Spain, and Japan gathered to discuss private life and public policy in a variety of conservative and fascist regimes during the $1920 \mathrm{~s}, 1930 \mathrm{~s}$, and 1940s. The papers clustered around three broad themes: the new images and ideologies about women developed in this period; the character and consequences of policies toward women as workers, wives, and mothers; and resistance and adaptation. In the opening session, the papers discussed the controversies about interpreting fascism currently going on in Germany and Japan. Questions were raised about the essential characteristics of these "dark times": when they began and ended, and which elements were most formative for women. Participants discussed the respects in which women were traditional and those in which they were modern-in images, ideologies, and reality, as well as how this shaped their position in the various economies and nation states.

Although the conference did not focus exclusively on working-class women, several papers did. In addition, the conference offered the opportunity to compare how class influenced gender, whether in the pervasive images of "new women" that were deployed by a variety of political movements and states, in the policies toward economic mobilization and pronatalism, or in the forms of resistance and adaptation to oppressive regimes. Probably the most innovative and valuable aspect of the conference was its inclusion of scholars working not only on several European countries but also on Japan and China. The discussions of Asia presented surprising similarities 
with the European situation in some instances, striking differences in others, and distinct cultural and class variations on Western themes in still others. Everyone was challenged to find concepts adequate to analyzing diverse women's situations in a world experiencing similar and related phenomena-a world sharing dark times.

\title{
Women's Worlds: The Third International Interdisciplinary Congress on Women
}

\author{
Miranda Pollard \\ Columbia University
}

The Third International Interdisciplinary Congress on Women was held July 6-10, 1987, at Trinity College, Dublin. Bringing together over 1,400 feminists from fortyeight countries to discuss the theme "Women's Worlds: Visions and Revisions," this conference was an eclectic and excitingly different event. Previous congresses, held in Haifa (1981) and Groningen (1984) on "The New Scholarship" and "Strategies of Empowerment," brought together scholars from different disciplines and established this international conference as an ongoing event. (The congresses are somewhat miraculously organized without a permanent secretariat or parent institution.) Dublin in 1987 witnessed the congress's transformation into a major feminist conference. Indeed as an academic/political event, it gave plenty of material for reflection, providing its participants with an engaging if kaleidoscopic view of women's studies and feminist agendas in the late 1980s.

The chief message may have been the plurality of feminisms and even of academic women's studies. Any report must be partial and somewhat arbitrary. A coherent intellectual critique of the proceedings would be impossible, given that seven hundred papers were presented over five days and that each participant took away a quite different impression, sharing for the most part only the daily plenary sessions and the overall sense of a busy and diverse occasion. There were multiple panels on a range of areas such as women's history, literature, women and health, ecology, linguistics, science, spirituality, poverty, education, reproductive technologies, and art, with no hegemony of one political or intellectual approach. The plenary sessions included lectures by Helen Caldicott (Australia), Mary Daly (United States), Kamla Bhasin (India), and Birgit Brock-Utne (Norway) on peace activism, women's language, and women and development. The aim was "to bring together scholars and practitioners from a wide range of disciplines and areas of expertise to jointly explore issues of importance to women throughout the world." To dismiss the event (as one colleague did) as "hardly cutting-edge" academically is to miss the point. This conference was not an elite, self-referential academic exercise, but a more ambitious political event (at least in theory), most closely resembling the annual National 